\title{
Technologies Needed for Sustainable E-Learning in University Education
}

\author{
N. E. Ibezim \\ Department of Vocational Teacher Education, University of Nigeria, Nsukka, Nigeria \\ Email: nnenna.ibezim@unn.edu.ng
}

Received July 16, 2013; revised August 15, 2013; accepted August 25, 2013

Copyright (c) 2013 N. E. Ibezim. This is an open access article distributed under the Creative Commons Attribution License, which permits unrestricted use, distribution, and reproduction in any medium, provided the original work is properly cited.

\begin{abstract}
This study was carried out to identify technologies needed for sustainable e-learning in university education. To achieve this objective, two research questions and one hypothesis were formulated, answered and tested respectively. Survey research design was used and a structured questionnaire was developed for data collection. A population of 330 information managers in information system units in federal universities in Nigeria was used for the study. The questionnaire was face-validated by three experts knowledgeable in e-learning application. An internal consistency co-efficient of 0.88 was obtained by using Cronbach alpha technique. Data collected from 322 of the respondents were analyzed for the study. Mean and standard deviation were used in data analysis, while ANOVA was used to test the hypothesis. The findings of the study revealed 13 communication technologies and 12 course management technologies needed for sustainable e-leaning in university education; and that there were no significant differences on the opinions of the information managers on 19 technologies needed for sustainable e-learning in university education. It was therefore recommended that the administrations of university education should make the identified technologies sufficiently available in order to sustain e-learning in the universities.
\end{abstract}

Keywords: Technologies; E-Learning; University Education

\section{Introduction}

University education, synonymous with tertiary education or higher education, is an educational level that follows the completion of a school providing a secondary education. It is usually referred to as the third level education and includes teaching, research, exacting applied work such as in the medical schools, and social service activities of universities. Within the realm of teaching, university education includes both the undergraduate and the graduate-level or postgraduate level for qualified students who wish to go further in their education and skills development [1]. These descriptions of the university education suggest that it has a wide range of students to attend to and thus requires suitable technologies that would satisfy the needs of these various classes of students.

Technology, according to Schatzberg [2], is the making, usage, and knowledge of tools, machines, techniques, crafts, systems or methods of organization in order to solve a problem or perform a specific function. It can also refer to the collection of such tools, machinery, and procedures involved in meeting a need. In the context of this study, technology refers to all the methods, tools, machinery and procedures that will enhance university education.

In this $21^{\text {st }}$ century, one of the tools used to enhance university education is the e-learning services. E-learning as recorded by Mayadas in Oakley [3] is a learning process in which learners can communicate with their instructors and their peers, and access learning materials, over the internet or other computer networks. E-learning is the application of the internet to support the delivery of learning skills and knowledge using a holistic approach which may not be limited to a particular course, technology or infrastructure. It provides flexibility which allows for just-in-time training when and where they are needed. E-learning creates room for integration into work place in terms of relevance, access to experts and collaboration for team working. Furthermore Curran [4], have defined e-learning as an innovative approach for delivering electronically mediated, well designed learner-centered and interactive learning environments to anyone, anyplace, and anytime by utilizing the internet and digital technologies in consonant with instructional design principles. E-learning brings proven benefits to students and lectur- 
ers in terms of cost effectiveness and efficiency, encouraging students to take responsibilities for their own learning which will be of benefit to them. E-learning brings learning to people, reduces cost of learning experiences and helps develop a more flexible innovation and creative students [5]. Liverpool, Marut, Ndam and Oti [6] further opine that technology — enhanced learning and online instruction, is recognized as a viable tool necessary for preparing citizens to participate in the technologically driven global environment. A multidisciplinary approach to online pedagogical research recognizes the value of technology_enhanced teaching and learning as critical in the mix of diverse strategies. Its centrality in the global marketplace has been enhanced by a new culture shared by many educators.

E-learning has been used very effectively in university teaching for enhancing the traditional forms of teaching and administration. Students on many courses in many universities in developed countries now have web access to the lecture notes and selected digital resources in support of their study, personalized web environments in which they can join discussion fora with their class or group, and this new kind of access gives them much greater flexibility of study. Part time students can more easily access their courses and this in turn supports the objectives of wider participation, removing the traditional barriers to higher education study [7]. Many nations in Africa today, have also embraced the e-learning technology especially in university education. Nigerian universities are not left out in the e-learning inventions. In most Nigerian universities, there are intensive efforts to put e-learning in place. E-learning has been practiced in one way or the other in the schools. However, when there is a need for enrollment into the schools through elearning channel, there seems to be hitches here and there, especially technologically. According to Ajadi, Salawu, \& Adeoye [5], e-learning in Nigerian universities and educational institutions is still a dream because of poor ICT infrastructure and other socio-economic reasons. The challenge facing Nigerian universities therefore, is how to sustain e-learning so as to avail the numerous students craving to be enrolled into the universities the opportunity with ease. This study therefore, sought to identify e-learning technologies that could be employed to sustain e-learning in the universities. Specifically, an attempt was made to determine:

1) The communication technologies needed for sustainable e-learning in university education.

2) The course management technologies needed for sustainable e-learning in university education.

\section{Research Questions}

1) What are the communication technologies needed for sustainable e-learning in university education?
2) What are the course management technologies needed for sustainable e-learning in university education?

\section{Hypothesis}

There is no significant difference in the mean ratings of responses of the information managers from the federal universities on the technologies needed for sustainable e-learning in university education.

\section{Methods}

The descriptive survey research design was adopted for the study. The study was conducted in the federal universities with Information Systems (IS) units in the six geopolitical zones of Nigeria. The population was 520 information managers from the 25 federal universities with Information Systems (IS) units. A sample size of 330 information managers obtained through a multistage sampling technique by selecting two universities from each of the six geo-political zones of Nigeria was used for the study and was distributed as follows: 52 from North West, 77 from South East, 35 from South West, 50 from North Central, 67 from South South, and 49 from North East. The instrument for data collection was a structured questionnaire on a 4-point scale as follows: Highly Needed (HN), Needed (N), Slightly Needed (SN), and Not Needed (NN) with weightings of $4,3,2$, and 1 respectively. The questionnaire was facevalidated by three experts and the Cronbach alpha technique was used to determine the internal consistency of the instrument, which yielded a coefficient of 0.88 .

The weighted mean was used to answer the research questions. The mean of the items was interpreted in relation to the real limit of numbers of the rating scale used for data analysis. Items with means ranging from 3.5 - 4.00 are classified as technologies that are highly needed for sustainable e-learning in university education; the items with mean ranging from 2.5 - 3.49 are classified as Needed technologies, those with mean ranges between $1.5-2.49$ as Slightly needed and items with mean ranging from $0.5-1.49$ are classified as technologies not needed for sustainable e-learning in university education. ANOVA statistic was used to test the null hypothesis. The null hypothesis of no significance was accepted for any item whose significant probability is greater than the significant probability level (0.05) used for testing the hypothesis, and was rejected if less. The standard deviation was used to determine the closeness or otherwise of the responses of the respondents to the mean. Any item with a low standard deviation indicated that there were less variations in the responses of the respondents, indicating that the mean values of the items were valid. 


\section{Results}

The results of the study were obtained from the research questions answered and hypothesis tested as shown in Tables 1 and 2.

\subsection{Research Question 1}

What are the communication technologies needed for sustainable e-learning in university education?

The data for answering the research question and testing the hypothesis are presented in Table $\mathbf{1}$.

The data presented in Table 1 revealed that 5 items had their mean values ranging from 3.54 - 3.85 indicating that the communication technologies represented by the items are highly needed for sustainable e-learning in university education. The Table also showed that 8 items had their mean ratings ranging from 3.18 - 3.47 indicating that the communication technologies represented by those items are also needed for sustainable e-learning in university education. The remaining two items had mean values which ranged from $2.06-2.17$, showing that the communication technologies represented by the items are slightly needed.

Table 1 further revealed that 5 items had their significant probability less than 0.05 , showing that for those items, the null hypothesis of no significance was rejected, while it was accepted for the remaining 10 items whose significant probability are greater than 0.05 .

Data in the table also showed that the standard deviation of the items ranged from $0.34-1.11$, which is a low range of values. The data further indicates that the respondents varied in their responses more on Text Notes $(\mathrm{SD}=1.11)$ as a communication technology needed for sustainable e-learning in university education than on the Internet technology $(\mathrm{SD}=0.34)$.

Chart 1 reveals that the Internet with a mean score of 3.85 is the most needed communication technology for sustainable e-learning in university education, followed by wikis and blogs with mean scores of 3.82 and 3.65 respectively. The chart also shows that the least needed communication technology is microphone rights with a mean score of 2.06 .

\subsection{Research Question 2}

What are the Course Management Technologies needed for sustainable e-learning in university education?

The data for answering the research question and testing the hypothesis are presented in Table 2.

Table 2 shows that 4 items had their mean values ranging from 3.50 - 3.85 indicating that the course management technologies represented by the items are highly needed for sustainable e-learning in university education. The Table further revealed that the remaining 8 items had their mean ratings ranging from 2.88 - 3.47, indicating that the course management technologies represented by those items are also needed for sustainable e-learning in university education.

Data in Table 2 further revealed that 3 items had their significant probability less than 0.05 , showing that for those items, the null hypothesis of no significance was

Table 1. Respondents mean scores and Analysis of Variance (ANOVA) on the communication technologies needed for sustainable e-learning in university education.

\begin{tabular}{|c|c|c|c|c|c|c|c|}
\hline \multirow{2}{*}{$\mathrm{S} / \mathrm{N}$} & \multirow{2}{*}{ Communication Technologies } & \multirow{2}{*}{$\mathrm{X}$} & \multirow{2}{*}{$\mathrm{SD}$} & \multirow{2}{*}{ F-cal } & \multirow{2}{*}{ Sig } & \multicolumn{2}{|c|}{ Remarks } \\
\hline & & & & & & RQ & Ho \\
\hline 1 & Blogs & 3.65 & 0.49 & 2.53 & 1.01 & Highly Needed & NS \\
\hline 2 & Wikis & 3.82 & 0.39 & 0.84 & 1.04 & Highly Needed & NS \\
\hline 3 & Discussion Boards & 3.47 & 0.79 & 0.24 & 0.00 & Needed & $\mathrm{S}$ \\
\hline 4 & E-mail & 3.54 & 0.56 & 2.54 & 0.06 & Highly Needed & NS \\
\hline 5 & Chat Rooms & 3.65 & 0.49 & 4.90 & 0.00 & Highly Needed & $\mathrm{S}$ \\
\hline 6 & Virtual Classrooms & 3.29 & 0.77 & 0.24 & 0.06 & Needed & NS \\
\hline 7 & Text Notes & 3.12 & 1.11 & 2.32 & 0.07 & Needed & NS \\
\hline 8 & Microphone Rights & 2.06 & 0.56 & 4.52 & 0.00 & Slightly Needed & $\mathrm{S}$ \\
\hline 9 & Breakout Sessions & 3.47 & 0.51 & 3.00 & 0.20 & Needed & NS \\
\hline 11 & Electronic Portfolios & 2.17 & 0.79 & 4.05 & 0.00 & Slightly Needed & S \\
\hline 12 & Websites & 3.47 & 0.51 & 2.53 & 0.54 & Needed & NS \\
\hline 13 & Collaborative Software & 3.18 & 0.73 & 2.91 & 0.09 & Needed & NS \\
\hline 14 & Interactive Laptops & 3.46 & 0.71 & 3.00 & 0.01 & Needed & NS \\
\hline 15 & Internet & 3.85 & 0.34 & 0.77 & 0.00 & Highly Needed & NS \\
\hline
\end{tabular}

NS: Not significant; S: Significant. 
Table 2. Respondents mean scores and Analysis of Variance (ANOVA) on the course management technologies needed for sustainable e-learning in university education.

\begin{tabular}{|c|c|c|c|c|c|c|c|}
\hline \multirow{2}{*}{$\mathrm{S} / \mathrm{N}$} & \multirow{2}{*}{ Course Management Technologies } & \multirow{2}{*}{$\mathrm{X}$} & \multirow{2}{*}{ SD } & \multirow{2}{*}{ F-cal } & \multirow{2}{*}{ Sig } & \multicolumn{2}{|c|}{ Remarks } \\
\hline & & & & & & RQ & Hypothesis \\
\hline 16 & Podcasts & 3.80 & 0.45 & 2.53 & 0.12 & Highly Needed & NS \\
\hline 17 & 3G mobiles & 3.59 & 0.37 & 5.87 & 0.00 & Highly Needed & S \\
\hline 18 & Search engines & 3.29 & 0.77 & 0.84 & 0.57 & Needed & NS \\
\hline 19 & Moodle & 3.50 & 0.66 & 2.60 & 0.69 & Highly Needed & NS \\
\hline 20 & E-college & 2.88 & 0.69 & 0.23 & 0.10 & Needed & NS \\
\hline 21 & Blackboard software & 3.85 & 0.44 & 2.15 & 0.14 & Highly Needed & NS \\
\hline 22 & Word processed documents & 3.47 & 0.51 & 5.26 & 0.00 & Needed & S \\
\hline 23 & PDF files & 2.94 & 1.03 & 1.44 & 0.20 & Needed & NS \\
\hline 24 & Streaming video and audio & 3.18 & 0.39 & 3.05 & 0.40 & Needed & NS \\
\hline 25 & $\begin{array}{c}\text { Computer aided testing and } \\
\text { assessment }\end{array}$ & 3.00 & 0.61 & 1.14 & 0.55 & Needed & NS \\
\hline 26 & $\begin{array}{l}\text { Educational animation, } \\
\text { simulation and games }\end{array}$ & 3.47 & 0.51 & 2.74 & 0.09 & Needed & NS \\
\hline 27 & Learning management systems & 3.35 & 0.41 & 4.13 & 0.01 & Needed & $\mathrm{S}$ \\
\hline
\end{tabular}

NS: Not significant; S: Significant.

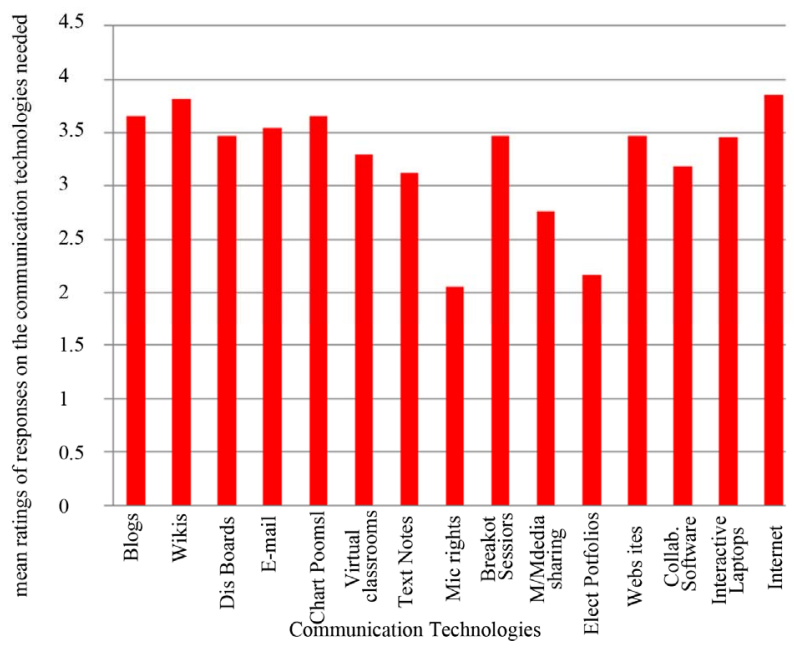

Chart 1. Bar chart of mean responses on the communication technologies needed for sustainble e-learning in university education.

rejected, while it was accepted for the remaining 9 items whose significant probability are greater than 0.05 .

The Table also showed that the standard deviation of the items ranged from $0.37-1.11$ which is a low range of values. The data further indicates that the respondents varied in their responses more on PDF Files (SD = 1.11) as a course management technology needed for sustainable e-learning in university education than on 3G Mobiles $(\mathrm{SD}=0.37)$.

Chart 2 reveals that the blackboard software with a mean score of 3.85 is the most needed course manage-

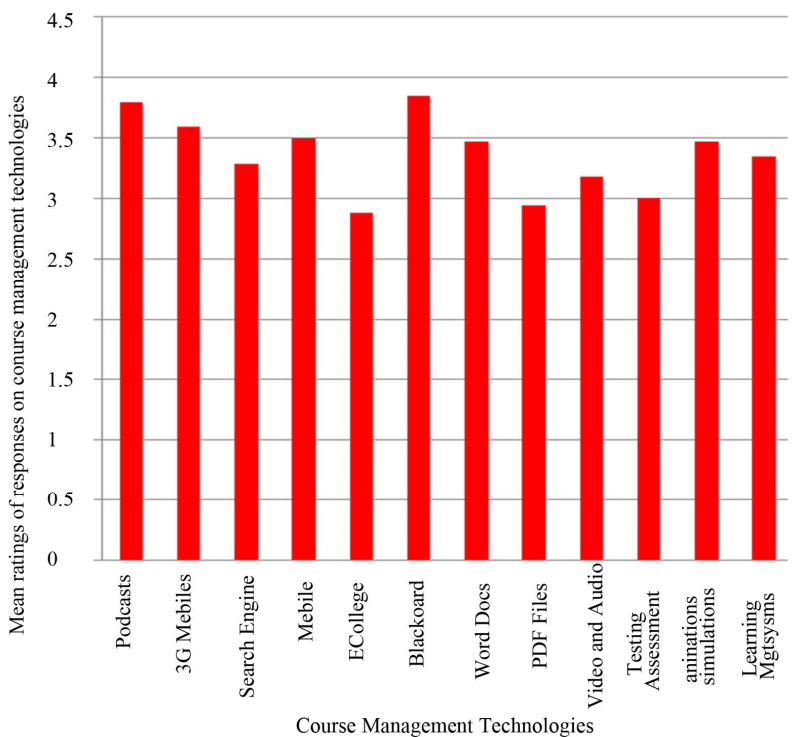

Chart 2. Bar chart of mean responses on the course technologies needed for sustainable e-learning in university education.

ment technology for sustainable e-learning in university education, followed by podcasts and 3G Mobiles with mean scores 3.80 and 3.59 respectively. The chart further revealed that the least needed course management technology is E-College with a mean score of 2.88 .

\section{Discussion of Results}

The study identified five communication technologies 
that are highly needed for sustainable e-learning in university education. Eight other communication technologies needed were also identified. These findings are in consonance with Shim, Shropshire, Park and Haris [8] who stated that corporate and e-learning trainers who are responsible for designing instruction must keep pace with changing training and education technology such as Blogs, Wiki, chats, e-mail and websites, to infuse eleaning into teaching and instructional models. The findings also agree with O'Hear [1] who recorded that blogging is increasingly finding a home in education (both in schools and universities), as not only does the software remove the barriers to writing and publishing, it encourages students to keep a record of their thinking over time. Blogs facilitate critical feedback, by letting readers add comments which could be from teachers, peers or a wider audience. Learning technologies have been developing haphazardly, and a little too rapidly for those who wish to turn them to advantage in learning. It becomes apparent to acclimatize to the new developments in information, communication, and delivery technologies such as Interactive computers, WIMP interfaces, Internet, Multimedia, Worldwide Web, Laptops, search engines, e-mail, 3G Mobiles and blogs for efficient learning [7]. Communication technologies are generally categorized as asynchronous or synchronous [9]. Asynchronous activities use technologies such as blogs, Wikis, and discussion boards. The idea here is that participants may engage in the exchange of ideas or information without the dependency of other participants' involvement at the same time. Electronic mail (Email) is also asynchronous in that mail can be sent or received without having both the participants' involvement at the same time. Furthermore, synchronous activities occur with all participants joining in at once, as with an online chat session or a virtual classroom or meeting. Virtual classrooms and meetings can often use a mix of communication technologies. Participants in a virtual classroom use icons called emoticons to communicate feelings and responses to questions or statements. Students are able to "write on the board" and even share their desktop, when given rights by the teacher. Other communication technologies available in a virtual classroom include text notes, microphone rights, and breakout sessions. Breakout sessions allow the participants to work collaboratively in a small group setting to accomplish a task as well as allow the teacher to have private conversations with his or her students.

The findings of the study also revealed four course management technologies that are highly needed for sustainable e-learning in university education. Eight other course management technologies needed for e-learning were also identified. This finding agrees with Rosen [10] who stated that Podcasting is a new technology that provides better services. The benefit of Podcasts is in its delivery mechanism and the ease of putting an audio on a Website and letting iPod users download it, then listen to the content through tapes. According to Shim, Shropshire, Park and Haris [8] a podcaster can record his own podcasts or listen to recorded podcasts of lectures to reinforce learning. The content once digitally recorded, can then be easily edited by the podcaster. Podcasts can also contain images, videos, and chapters identifying major sections or ideas. In a course management system, the following technologies are expected: Blackboard, eCollege, or Moodle; Word processing documents such as. DOC or PDF files; Streaming audio, video, and podcasts, textbooks and printed literature. In a virtual classroom, one is likely to encounter a lot of reading of handouts that consist of Word documents and PDF files. However, in recent years, online schools have stepped up and advanced their offerings as one may find that the courses make a good deal of use of streaming audio and video, where you listen to or even watch a lecture or other resource right on your screen. Sife, Lwoga, and Sanga [11] had earlier confirmed that e-learning platforms are sustained by using WEBCT and Blackboard, which are e-learning proprietary software. Furthermore, once computers and a network are in place, e-learning activity can commence [6]. At this stage, the use of CDs and other intranet resources such as the e-granary is critical. Once Internet access is in place, the creation of digital local content stimulates the rapid use of ICT especially if this local content drives users to complimentary web resources [12].

Data from the hypothesis tested in the study, revealed that there were no significant differences in the mean ratings of the responses on 10 communication technologies and 9 course management technologies for sustainable e-learning in university education, while in 5 communication technologies and 3 management technologies, the hypothesis was rejected. The implication of these findings is that for the items where the hypothesis was accepted, despite the differences in institution and structure of learning, their opinions were not significantly influenced on the 19 technologies needed for sustainable e-learning in university education. Their opinions however, were significantly influenced on 8 technologies, implying that there may be variations in the extent of utilization of those technologies by the institutions.

\section{Conclusion}

E-learning is fast growing in many schools and universities because of the numerous advantages, it avails both teachers and students. However, it is important also to know that there are necessary technologies that must be on the ground in order to sustain e-learning. This study identified the communication technologies and course management technologies that are needed for sustainable 
e-learning in university education. Some of these needed communication technologies identified are Blogs, Wikis, chat room, and Internet; while Podcasts, 3G Mobiles, World Wide Web, and Moodle are course management technologies identified for sustainable e-learning.

\section{Recommendations}

Based on the findings and conclusions drawn from the study, the following recommendations are proffered:

Administrators of universities should endeavour to adequately provide the communication and course management technologies identified in order to sustain e-learning.

Lecturers and students should be encouraged to utilize the identified technologies for enhanced teaching and learning.

\section{REFERENCES}

[1] S. O’Hear, “E-Learning 2.0-How Web Technologies Are Shaping Education, 2006.

http://www.readwriteweb.com/archives/e-learning_20.php

[2] E. Schatzberg, “Technik Comes to America: Changing Meanings of Technology before 1930," Technology and Culture, Vol. 47, No. 1, 2006, pp. 486-512. http://dx.doi.org/10.1353/tech.2006.0201

[3] B. Oakley, "Learning Effectiveness: An Introduction,” In: J. Bourne, Ed., On-Line Education: Learning Effectiveness and Faculty Satisfaction, Vol. 16, No. 2, 2000, pp. 45-55.

[4] C. Curran, "Strategies for E-Learning in Universities," Re- search \& Occasional Paper Series: CSHE.7.04. Dublin City University, Dublin, 2004.

[5] T. O. Ajadi, I. O. Salawu and F. A. Adeoye, "E-Learning and Distance Education in Nigeria,” The Turkish Online Journal of Educational Technology, Vol. 7, No. 4, 2008.

[6] L. S. O. Liverpool, M. J. Marut, J. N. Ndam and D. A. Oti, "Towards a Model for E-Learning in Nigerian HEIs: Lessons from the University of Jos ICT Maths Initiative," 2009. www.forum.org.ng/system/files/ife+paper.pdf

[7] D. Laurillard, "E-Learning in Higher Education," Changing Higher Education, RoutledgeFalmer, New York, 2009.

[8] J. P. Shim, J. Shropshire, S. Park and H. Haris, "Podcasting for E-Learning, Communication, and Delivery," Industrial Management and Data Systems, Vol. 107, No. 4, 2007, pp. 587-600. http://dx.doi.org/10.1108/02635570710740715

[9] Wikipedia (2012) “E-Learning,” 2012. http://www.en.wikipedia.org/wiki/E-learning

[10] A. Rosen, "Technology Trends: E-Learning 2.0. The ELearning Guild's Learning Solutions,” Practical Applications of Technology for Learning E-Magazine, Management Strategies Edition, 2006.

[11] A. S. Sife, E. T. Lwoga and C. Sanga, "New Technologies for Teaching and Learning: Challenges for Higher Learning Institutions in Developing Countries,” International Journal of Education and Development Using Information and Communication Technology, Vol. 3, No. 2, 2007, pp. 57-67.

[12] "What Technologies Are Used in Online Education?" 2012.

http://www.elearners.com/guide/faq-glossary/elearning-fa q/what-technologies-are-used-in-online-education/ 